\title{
Maternal Vitamin D3 Status and Association with Low Birth Weight Infant
}

Raghad Farhad Ahmed; Maternity Teaching Hospital/ Erbil Directorate of Health/ Ministry of Health, Erbil, Iraq. (Correspondence: blackpears2001@yahoo.com)

Hanaa Al.Ani; Department of Nursing, College of Nursing, Hawler Medical University, Erbil, Iraq.

\section{ABSTRACT}

Background and Objective: Maternal vitamin D levels may affect fetal growth and cause adverse pregnancy outcomes including low birth weight in neonatal stage. This study was designed to evaluate and determine if the deficiency of maternal Vitamin $D$ associated and affected the growth development of birth weight of neonates.

Methods: This study was carried-out on 200 neonates through a cross-sectional study, that used data from the nursery ward at maternity teaching hospital hospitals in Kurdistan, Iraq during a one year period from March 2016 to March 2017. The neonates were divided into two group two groups, neonates with birth weight $<2500 \mathrm{gr}(\mathrm{n}=45)$ and neonates with birth weight $>2500 \mathrm{gr}(n=55)$. We depend on the data classifications on medical history, physical examination using a questionnaire method for neonate classifications. Birth time blood samples of their mothers were analyzed for serum 25-(OH)-vitamin D using enzyme linked immunosorbent assay method. Maternal vitamin $D$ status was compared in the two groups.

Results: The mean maternal vitamin D level was $24 \mathrm{nmol} / \mathrm{L}$. for mothers with low birth weight and 22 (48.89\%) for mothers with vitamin D deficiency. Seventeen (37.77\%) and 6 (13.34 \%) of the mothers with low birth weight had insufficient vitamin D and 6 (13.34 \%) had normal Vitamin $D$ levels. The mothers with normal birth weight had a mean vitamin $D$ level of $38.10 \mathrm{nmol} / \mathrm{L}$ and the mothers of low levels reached to $10 \mathrm{nmol} / \mathrm{L}(18.18 \%)$, those of insufficiency vitamin D was $20 \mathrm{nmol} / \mathrm{L}(36.36 \%)$ and those of sufficient vitamin D 25 $\mathrm{nmol} / \mathrm{L}$ (45.46\%).

Conclusion: Mothers with low vitamin D levels are more likely to have neonates with low birth weight. Increasing the vitamin D levels through nutrition is important for improving the neonatal body weight.

Keywords: Infant, Low birth weight, vitamin D Deficiency

\begin{tabular}{|c|c|}
\hline Received: $1 / 8 / 2018$ & Published: 3011/2018 \\
\hline $\begin{array}{l}\text { INTRODUCTION } \\
\text { Vitamin D affects fetal growth by its } \\
\text { interaction with Ca2+ homeostasis and } \\
\text { parathyroid hormone. Few studies have } \\
\text { been conducted to detect vitamin D status } \\
\text { in mothers in Iran. In recent study, nearly } \\
\text { half of our mothers had vitamin D } \\
\text { deficiency. Low vitamin D and } \\
\text { osteomalacia in south Asian pregnant } \\
\text { women have been widely reported [1,2]. }\end{array}$ & $\begin{array}{l}\text { Some investigations have pointed to the } \\
\text { effect of micronutrients on birth weight } \\
\text { [3]. Vitamin D stressing has a key role in } \\
\text { fetal growth by its interaction with } \\
\text { parathyroid hormone and calcium } \\
\text { homeostasis. Studies have confirmed that } \\
\text { insufficient prenatal levels of vitamin D has } \\
\text { a strong effect on poor bone } \\
\text { mineralization, which has a significant } \\
\text { association with small-for-gestational- age } \\
\text { births [4]. Low birth weight (LBW) refers to }\end{array}$ \\
\hline
\end{tabular}


term or preterm neonates with birth weight $<2500$ gr. These neonates may be small for gestational age or have intrauterine growth restriction. Mortality rate in such neonates is 40 times more than those with normal weight [3]. Vitamin $D$ deficiency has been seen among people all over the world [5].

The aim of this study was to evaluate the relationship between maternal vitamin $D$ status and neonate birth weight because research suggest that low serum maternal vitamin D may impair fetal growth and cause adverse pregnancy outcomes including intrauterine growth restriction and neonatal low birth weight.

\section{METHODS}

Two-hundred mothers participated in this cross-sectional study. Data were collected from the labor ward of Maternity Teaching Hospitals in Kurdistan, Iraq from March 2016 to March 2017. We took a blood sample after delivery and sent it to a private laboratory. The neonates were divided into two groups, neonates with birth weight $<2500 \mathrm{gr}(\mathrm{n}=45)$ and neonates with birth weight $>2500 \mathrm{gr}(\mathrm{n}=55)$, depending on the data classifications including from medical history, physical examination, and anthropometric measurements of neonates using a questionnaire method for neonates classifications. Birth time blood samples of their mothers were analyzed for serum 25-(OH)-vitamin D and Maternal vitamin D status was compared in studied groups. The inclusion criteria include otherwise healthy women aged 21 to 35 years, having a singleton pregnancy and a term pregnancy. The exclusion criteria included mothers with preeclampsia, eclampsia, postpartum hemorrhage, insulin dependent diabetes mellitus, systemic and chronic disease, hematologic disorders, infections. Questionnaires filled out and recorded neonatal birth weight and height, gestational age, mode of delivery, mother's age, parity, race, mother's education and clinical vitamin $D$ deficiency symptoms. Immediately after birth, $5 \mathrm{ml}$ of mother's blood was collected, labeled and sent to laboratory to assay serum 25- $(\mathrm{OH})$-vit D level by 25-Hydroxy Vitamin D Enzyme immunoassay method. Depending on mothers' 25- $(\mathrm{OH})$-vitamin D level, all mothers were categorized in deficient $(<25 \mathrm{nmol} / \mathrm{L}$ ), insufficient (should be defined at thresholds of $75 \mathrm{nmol} / \mathrm{L}$ or even higher which would require a much higher intake to reach.)[6,7]. (25-50 nmol/ L), normal (>50nmol/L).

Statistical analysis of the data was carried-out using SPSSPC+ version 16. Data are presented as mean and standard deviation for continuous variables and $n \%$ for categorical variables. The Chi Square, $T$ test, Chi-square test and Logistic regression were applied where applicable at the level of significance $(p<0.05)$.

\section{RESULTS}

The mean $\pm S D$ of maternal serum vitamin $D$ level in all 200 mothers was $33.26 \pm 2.65$ $\mathrm{nmol} / \mathrm{L}$, mean $\pm \mathrm{SD}$ of age was $23.32 \pm 3.61$ years, and mean \pm SD gestational age in

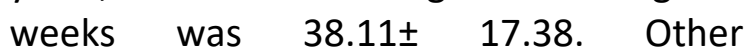
demographic characteristics are shown in Table 1.

Table 1: Demographic characteristics of the study sample

\begin{tabular}{ll}
\hline Demographic characteristics & Mean \pm SD \\
\hline Gestational age/ week & $38.11 \pm 17.38$ \\
Maternal age/year & $23.32 \pm 3.61$ \\
Birth weight/gm & $2645.2 \pm 35.39$ \\
Neonatal height (Cm) & $46.08 \pm 4.31$ \\
Head-circumference (Cm) & $33.51 \pm 3.39$ \\
Maternal serum vitamin D & $33.26 \pm 2.65$ \\
nmol/l & \\
\hline
\end{tabular}


Table 2 shows the differences of serum vitamin $D$ levels among mothers with normal birth weight neonates $(39.14 \pm 3.15)$ and mothers of LBW neonates (27.38 \pm 2.15$),(P<0.01)$.

Table 3 shows the vitamin $D$ serum level in mothers with LBW \& normal birth weight neonates.
There was a significant difference, with $70 \%$ of the mothers with sufficient level of vitamin $D$ giving birth to neonates with birth weight $\geq 2500 \mathrm{gm}$ and $50 \%$ of mothers with deficient vitamin $\mathrm{D}$ giving birth to neonates with low birth weight.

In Table 4, there was no significant difference in the mode of delivery with maternal vit. $D$ level $(P=0.3220)$.

Table 2: Maternal Vitamin D level in both study groups

Groups Vit $D$ serum level

\begin{tabular}{lr}
\hline Mothers with neonate $\geq \mathbf{2 5 0 0}$ gm & $39.14 \pm 3.15$ \\
Mothers with neonate $\leq \mathbf{2 5 0 0} \mathbf{g m}$ & $27.38 \pm 2.15$
\end{tabular}

$*(P<0.01)$

$*(P<0.01)$

Table 3: Level of vitamin D and relationship with neonatal birth weight

\begin{tabular}{|c|c|c|c|}
\hline & $\begin{array}{l}\text { Sufficiency } N \\
\text { (\%) }\end{array}$ & $\begin{array}{l}\text { Insufficiency } \\
N(\%)\end{array}$ & $\begin{array}{l}\text { Deficiency } \\
\text { N (\%) }\end{array}$ \\
\hline $\begin{array}{l}\text { Mothers of normal birth weight } \\
\text { neonate }\end{array}$ & $70(70)$ & $20(20)$ & $10(10)$ \\
\hline Mothers of LBW neonate & 15 (15 \%) & $35(35 \%)$ & $50(50)$ \\
\hline
\end{tabular}

$*(P=0.3220)$

Table 4: Relationship of vit $D$ and mode of delivery

\begin{tabular}{lcccc}
\hline Mode of delivery & \multicolumn{2}{l}{ Hypovitaminosis D } & \multicolumn{2}{l}{ Normal Vit.D level } \\
\hline & $\mathbf{N}$ & \% & $\mathbf{N}$ & $\%$ \\
Cesarean Section & 45 & 46.4 & 52 & 53.6 \\
Normal Vaginal Delivery & 55 & 53.4 & 48 & 46.6 \\
\hline
\end{tabular}




\section{DISCUSSION}

The results from this study are comparable to both national and international studies reporting on the high prevalence of vitamin $D$ deficiency in pregnant women. Vitamin $D$ has well-defined classical functions related to calcium metabolism and bone health, as well as non-classical effects that may influence other aspects of health. There has been considerable recent interest in the role of vitamin $D$ on outcomes related to pregnancy and young child health, but few efforts have been made to systematically consolidate this evidence to inform the research and policy agenda for low-income countries [8]. Vitamin D affects fetal growth by its interaction with $\mathrm{Ca} 2+$ homeostasis and parathyroid hormone. Few studies have been conducted to detect vitamin $D$ status in mothers in Iran. In recent study, nearly half of our mothers had vitamin D deficiency. Hypovitaminosis $D$ and osteomalacia in South Asian pregnant women have been widely reported, too $[1,2]$.

Our results suggested that there is a significant correlation between LBW and maternal vitamin $D$ deficiency. Our results agree with findings from Bodnar et al. (2010), which found positive relationship between vitamin $D$ deficiency in white mothers and neonatal LBW and a significant correlation between LBW and maternal vitamin $D$ deficiency $[9,10]$. They showed a positive relationship between vitamin $D$ deficiency in white mothers and neonatal LBW. Another study from the Ali Aghar Hospital of the Iran University of Medical Sciences, Tehran, Iran also showed that maternal vitamin $D$ deficiency may increase the risk of low birth weight neonate and that adding supplements of vitamin $D$ could be beneficial on pregnancy outcomes. Safety of vitamin D supplements and fortification have been proved by some articles. Mothers using vitamin D supplementation (400-4000 IU/day) in 1216 weeks showed lower preterm risks [11]. While, those of vit $D$ deficient mothers (25 Hydroxy Vit $D<30$ ) have two-times the chance of giving birth small for gestational age (SGA) babies in compare to those with adequate vitamin D status [12]. The World Health Organization (WHO) has shown the importance of micronutrients including vitamin $D$, in increasing about 77 gr birth weights and $25 \%$ decrease of LBW [3]. This recommendation was contentious as many researchers have argued that insufficiency should be defined at thresholds of 75 $\mathrm{nmol} / \mathrm{L}$ or even higher, which would require a much higher intake $[6,7]$. Several recent reviews have covered a rapidly growing body of literature on vitamin $D$ during pregnancy [14], although few have taken a systematic approach (18) and only a couple have focused on the implications for low income country settings [13]. This recommendation was based on the amount of intake necessary to sustain blood levels of 25(OH)D above 50nmol/L for populations with minimal sunlight exposure and was developed solely based on outcomes related to skeletal health [7]. This recommendation was contentious as many researchers have argued that insufficiency should be defined at thresholds of $75 \mathrm{nmol} / \mathrm{L}$ or even higher which would require a much higher intake to reach $[6,7]$. Although a significant difference was found between the mode of delivery and mother's vit D status, our finding was against investigation from Dror et al [14].

\section{CONCLUSIONS}

Our results indicated that the high prevalence of vitamin D deficiency has been seen among women especially in developing countries and that neonatal low birth weight (LBW) could be related to 
maternal vitamin D deficiency. Modifying maternal nutrition behavior and vitamin $D$ level could be beneficial on prevention of low birth weight. However, more research in this field would contribute to an improvement in maternal and neonatal health.

\section{CONFLICT OF INTEREST}

The Author report no conflict of interest

\section{REFRENCES}

[1] Sioen I, Mouratidou T, Kaufman JM, Bammann K, Michels N, Pigeot I, et al. Determinants of vitamin $D$ status in young children: results from the Belgian arm of the IDEFICS (Identification and Prevention of Dietary- and LifestyleInduced Health Effects in Children and Infants) Study. Public Health Nutrition. 2012;15:1093-9.

[2] Patel M, Beg m, Akhtar N, Ahmad J, Farooqui Kh. Serum calcium, vitamin D and parathyroid hormone relationship among diabetic And nondiabetic pregnant women and their neonates. Diabetes \& Metabolic Syndrome: Clinical Research \& Reviews. 2010;4:204-9.

[3] Thorne-Lyman A, Fawzi W. Vitamin D during pregnancy and maternal, neonatal and infant health outcomes:A systematic review and meta-analysis. Pediatric and Perinatal Epidemiology. 2012;26:75-90.

[4] Bodnar L M, Catov J M, Zmuda J M, Cooper M E, Parrott MS, Roberts J M, et al. Maternal serum 25-hydroxyvitamin D concentrations are associated with small-for-gestational age births in white women. Journal Nutrition. 2010; 140:999-1006.

[5] Fernández-Alonso AM, Dionis-Sánchez EC, Chedraui P, González-Salmerón MD, Pérez-López FR. Women's Health Research Group. Spanish Vitamin D and Women's Health Research Group.Firsttrimester maternal serum 25hydroxyvitamin D-status and pregnancy outcome. International Journal of Gynaecology and Obstetrics. 2012;116:69.
[6] Leffelaar ER, Vrijkotte TG, van Eijsden $M$. Maternal early pregnancy vitamin $D$ status in relation to fetal and neonatal growth: results of the multi-ethnic Amsterdam Born Children and their Development cohort. British Journal Nutrition. 2010;104:108-17.

[7] Dror D, King J, Durand D, Allen L. Association of Modifiable and Nonmodifiable Factors with Vitamin D Status in Pregnant Women and Neonates in Oakland. Journal of the Academy of Nutrition and Dietetics. 2011; (111):111-6.

[8] Bodnar LM, Simhan HN, Powers RW, Frank MP, Cooperstein E, Roberts JM. High prevalence of vitamin $D$ insufficiency in black and white pregnant women residing in the northern United States and their neonates. Journal Nutrition. 2007;137(2):447-52.

[9] Merewood A, Mehta SD, Chen TC, Bauchner $\mathrm{H}$, Holick MF. Association between vitamin $\mathrm{D}$ deficiency and primary cesarean section. Journal of Clinical Endocrinology and Metabolism. 2009; 94(3):940-945.

[10] Martin RJ, Fanaroff AA, Walsh MC. (2005): Fanaroff and Martin's Neonatal-Perinatal Medicine: Diseases of the Fetus and Infant. 8th ed. Mosby; 2005.

[11] Thorne-Lyman A, Fawzi WW. Vitamin D during pregnancy and maternal, neonatal and infant health outcomes: a systematic review and meta-analysis. 
Paediatric and Perinatal Epidemiology. 2012 Jul;26 Suppl 1:75-90.

[12] Arabi A, El Rassi R, El-Hajj Fuleihan G. Hypovitaminosis $D$ in developing countries-prevalence, risk factors and outcomes. Nature Reviews Endocrinology. 2010;6(10):550-561.

[13] Barrera D, Avila E, Hernandez G, Halhali A, Biruete B, Larrea F, et al. Estradiol and progesterone synthesis in human placenta is stimulated by calcitriol. Journal of Steroid Biochemistry and Molecular Biology. 2007;103(35):529-532.

[14] Hollis BW. Vitamin D requirement during pregnancy and lactation. Journal of Bone and Mineral Research. 2007;22 (Suppl 2):V39-44.

[15] Holick MF. Vitamin D deficiency. New England Journal of Medicine.2007; 357:266-281.

[16] Patel M, Beg M, Akhtar N, Ahmad J, Farooqui Kh. Serum calcium, vitamin $\mathrm{D}$ and parathyroid hormone relationship among diabetic And nondiabetic pregnant women and their neonates. Diabetes \& Metabolic Syndrome.Clinical Research \& Reviews. 2010;4:204-9.

[17] Institute of Medicine. (2011): Dietary reference intakes for calcium and vitamin D. Washington, DC: The National Academies Press.

[18] Mahomed K, Gulmezoglu AM. Vitamin $D$ supplementation in pregnancy. Cochrane Database of Systematic Reviews. 2000 ;(2):CD000228.

[19] Dawodu A, Wagner CL. Mother-child vitamin $D$ deficiency: an international perspective. Archives of Disease in Childhood. 2007; 92(9):737-740.

[20] Aghajafari F, Nagulesapillai T, Ronksley $\mathrm{PE}$, Tough SC, O'Beirne M, Rabi DM. Association between maternal serum 25-hydroxyvitamin D level and pregnancy and neonatal outcomes: systematic review and meta-analysis of observational studies. British Medical Journal. 2013;346:f1169. doi: 10.1136/bmj.f1169.

[21] Scholl TO, Chen X. Vitamin D intake during pregnancy: association with maternal characteristics and infant birth weight. Early Human Development. 2009;85(4):231-4. 